\title{
Relationship between nurses' and physicians' perceptions of organizational health and quality of patient care
}

\author{
A.H.M. Hussein ${ }^{7}$
}

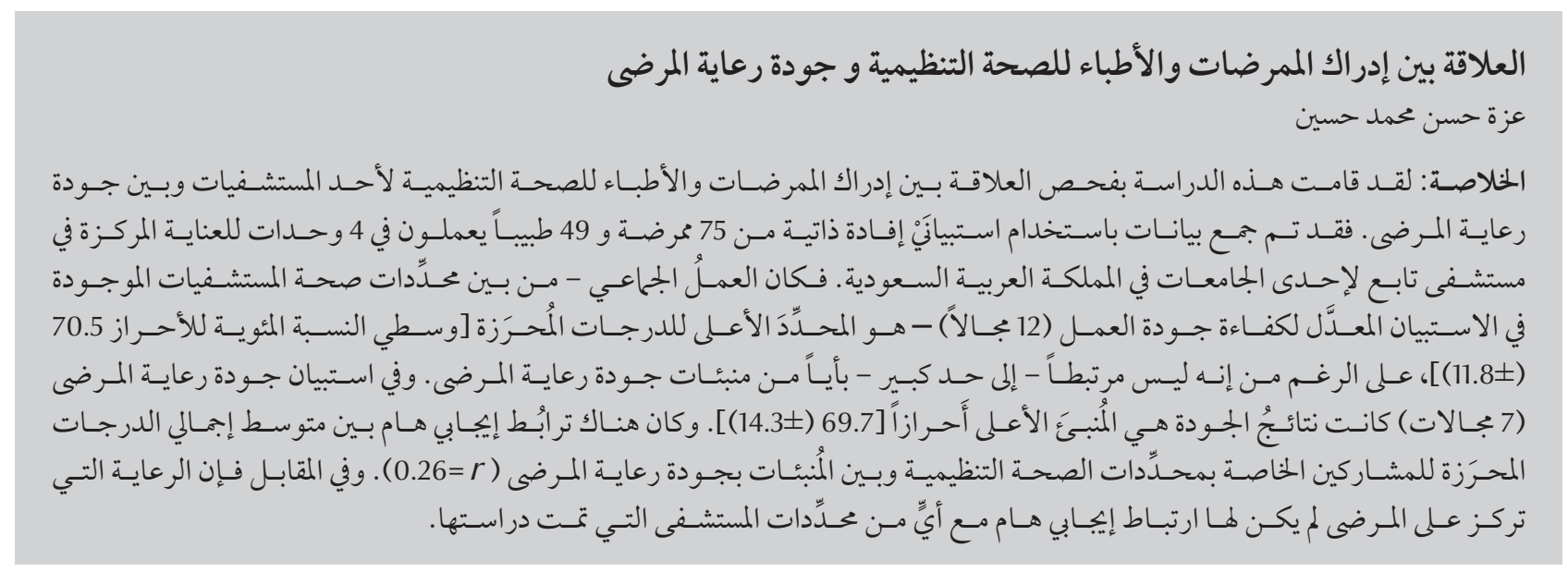

ABSTRACT This study investigated the relationship between nurses' and physicians' perceptions of the organizational health of a hospital and the quality of patient care. Data were collected using 2 self-report questionnaires from 75 nurses and 49 physicians working in 4 intensive care units in a university-affiliated hospital in Saudi Arabia. Among the determinants of hospital health in the modified Quality Work Competence questionnaire (12 domains), teamwork was the highest scoring determinant [mean percentage score 70.5 (SD 11.8)]; however it was not significantly correlated with any of the predictors of quality of patient care. In the Quality of Patient Care questionnaire (7 domains) quality results was the highest scoring predictor [69.7 (SD 14.3)]. There was a significant positive correlation between participants' perception of overall mean percentage scores on the determinants of organizational hospital health and the predictors of the quality of patient care $(r=0.26)$. In contrast, patient-centred care had no significant positive correlation with any of the studied hospital health determinants.

Relation entre la perception du personnel infirmier et des médecins à l'égard de la santé organisationnelle et la qualité des soins aux patients

RÉSUMÉ La présente étude a évalué la relation entre la perception du personnel infirmier et des médecins à l'égard de la santé organisationnelle d'un hôpital et de la qualité des soins aux patients. Les données ont été recueillies à l'aide de deux autoquestionnaires remplis par 75 membres du personnel infirmier et 49 médecins travaillant dans quatre unités de soins intensifs d'un hôpital affilié à une université en Arabie saoudite. Parmi les déterminants de la santé hospitalière dans la version modifiée du Quality Work Competence questionnaire (12 domaines), le travail d'équipe était le déterminant ayant le score le plus élevé [pourcentage moyen 70,5 (ET 11,8)], mais n'était fortement corrélé à aucun des facteurs prédictifs de la qualité des soins aux patients. Dans le Quality of Patient Care questionnaire (7 domaines), les résultats concernant la qualité étaient les facteurs prédictifs ayant le score le plus élevé $[69,7$ (ET 14,3)]. Il existait une corrélation fortement positive entre la perception qu'ont les participants des scores moyens globaux exprimés en pourcentage pour les déterminants de la santé organisationnelle et les facteurs prédictifs de la qualité des soins aux patients $(r=0,26)$. En revanche, les soins axés sur le patient n'avaient pas de corrélation significativement positive avec les déterminants hospitaliers étudiés.

'Nursing Administration Department, Faculty of Nursing, Alexandria University, Alexandria, Egypt (Correspondence to: aza.hussein@alexnursing.edu.eg).

Received: 16/06/13; accepted: 19/03/14 


\section{Introduction}

Over the past decade there has been a growing body of workplace health research that has moved beyond assessing individual employees' wellbeing to investigating the workplace determinants of wellness and job performance and how organizational health might contribute to the delivery of quality patient care in health-care agencies $(1-3)$. It is now common knowledge that the quality of health systems and their performance and services can be assessed by considering the essential features of so-called "healthy workplaces" (4). Organizational health refers to an organization's ability to achieve sustainable outcomes and to cope appropriately with its environment, to enhance organizational performance and to support employees' well-being $(1,5)$.

Organizational health audits provide the means whereby health-care organizations such as hospitals can continuously learn how to improve themselves $(6,7)$. The organizational health of a hospital encompasses all the psychological, physiological and social components of the organizational system - all the distinctly human parts $(8,9)$, organizational processes and culture elements that contribute to organizational function and capacity $(8,10)$. If these elements are designed inappropriately or incongruently this can negatively affect the quality of patient care. Given the assumption that many nurses and physicians are full participants and significant players in key committees and hospital performance, this research can have profound implications in creating a healthy hospital. Understanding hospital organizational health may help its managers to build strong hospital systems, maintain nurses' and physicians' well-being, as well as improve the quality of patient care. The latter could be achieved by studying how hospital workplace health could be a predictor of patient care quality.
The present study was guided mainly by the conceptual framework of organizational health developed by Arnetz in 1997and $2005(11,12)$. This concept concerns the psychosocial work conditions and work organization at every workplace (13) and rests on 12 fundamental determinants-goal/organizational clarity, performance feedback, participatory management, leadership, organizational efficacy, change motivation, competence development, work climate, mental energy/emotional exhaustion, work intensity/tempo, internal communication $(11,12)$ and teamwork (14). It was hypothesized that these hospital health determinants could predict the extent of quality of patient care. The assessment of quality of care was based on the work of the Institute of Medicine (IOM) to identify the components of quality of patient care for the 21 st century whereby health care should be: patient-centered, effective, safe, timely, efficient and equitable (15).

Intensive care units (ICUs) are recognized as especially stressful environments. However, the conditions in which stressors may affect health professionals' performance and wellbeing and the conditions that potentially lead to impaired performance and staff psychological distress are not well understood $(16,17)$. Health-care professionals face many demands, both externally from the world around and internally from their own health-care organizations. These demands can result in ill health and work exhaustion $(17,18)$. High levels of stress among health professionals can also negatively affect patients' outcomes $(19,20)$.

The objectives of this study were to investigate the relationship between ICU nurses' and physicians' perceptions of the organizational health of a hospital and the quality of patient care; and to assess and compare the perceptions of nurses and physicians. The purpose was not only to identify the present work situation but also to identify its characteristics, to target possible causes of organizational ill health and then to focus on the required improvement efforts.

\section{Methods}

\section{Study design and setting}

A comparative, correlational design was followed in this study. The study was carried out in 4 ICUs - paediatric, neonatal, medical and surgical - at one of the university hospitals in Saudi Arabia. These units incorporate many characteristics of well-defined organizational and clinical practice, formed on the basis of internationally recognized guidelines and an operational philosophy/goal of quality of patient care. They are equipped with modern, complex technologies such as clinical computer systems and digital diagnostic medical machines, act as centres of excellence in some types of research and have an executive information system; however, they are intensely interactive workplaces with hazardous environments. The study hospital underwent an accreditation process from 2007-08, and 6 months before data collection the hospital was in the process of renewing its accreditation status.

This hospital is one of the independent government bodies that serve particular populations. It works under the umbrella of the Saudi Arabian Ministry of Higher Education (University Hospitals) and it is totally owned and financed by the government to serve particular populations. All health services that are provided by the government sector are free of charge. Health-care personnel are reimbursed by monthly salaries while the facilities are funded by annual budgets. The objectives are geared towards educating and training current and future health professionals, exploring new areas of research and providing high-quality, compassionate health care by well-trained and specialized health professionals. 
The hospital has a decentralized health-care delivery system and management authority which is responsible for developing its strategic planning, formulating specific health policies and supervising health-service delivery programmes. Strategic decision-making is mainly taken by top management with some level of participation from the operational staff such as nurses and physicians. It has the accountability for planning, training and management of human health resources and achieving health outcomes. Nurses' and physicians' performance is reviewed annually through a meeting with their direct supervisor.

\section{Sample}

The study participants included 77 nurses and 51 physicians who were working in the studied ICUs and had sufficient work experience in their current work unit to be able to assess the studied variables (at least 1 year of experience). Overall 75 out of 77 nurses and 49 out of 51 physicians completed and returned the questionnaires.

\section{Data collection}

Collection of data was done from 17 April to 10 June 2010. The questionnaires were hand delivered by the current researcher to each participant in the beginning of his/her morning shift or during break time in the work unit. Completion of the questionnaires was done through self-reporting and each participant needed about 45 minutes to complete both questionnaires.

\section{Study tools}

Two tools were used in this study. The first was the Quality Work Competence questionnaire, which was developed (21) and modified by Arnetz $(11,12,22)$. This was adapted by the current researcher from the original 42 -item version - to be suitable to this hospital culture, to facilitate assessment and to add to what was already known - into a validated, 80-item questionnaire that covered nurses' and physicians' perceptions in relation to 12 determinants of hospital health. These were: goal/organizational clarity (e.g. hospital goals are clearly stated); performance feedback (e.g. continuous feedback is given to employees about their performance); participatory management (e.g. work objectives and plans are developed jointly); leadership (e.g. immediate supervisor coaches employees to solve their problems); internal communication (e.g. information flows freely in the work unit); organizational efficacy (e.g. the decision-making process is functional); competence development (e.g. there is a chance to attend training programmes); work climate (e.g. there are supportive colleagues); mental energy/emotional exhaustion (e.g. during work I feel stress); work intensity/tempo (e.g. enough time is available to carry out work); change motivation (e.g. the management provides recognition of any new achievements) (12); and teamwork (e.g. both nurses and physicians consider the experience of each other) (23). The responses were measured on 4-point Likert scales ranging from strongly agree (4) to strongly disagree (1). Mental energy statements were reverse scored - the fewer the symptoms, the higher the score. The higher the score the healthier the hospital was perceived to be. The overall scores of these determinants constituted the focus score enhancement index.

For the purpose of the present study, the current author developed the Quality of Patient Care questionnaire based on the current literature (24-26). It consisted of 33 statements grouped into 7 predictors to measure the quality of care provided to all patients eligible for ICU services, as perceived by the participants. A total of 29 statements measured the first 6 predictors derived from the IOM's aims (24) including: patient-centred care (e.g. continuous feedback given to patients and family); effectiveness (e.g. health care is an evidence-based practice); safety (e.g. patient privacy is maintained); timeliness (e.g. care is given at the exact time); efficiency (e.g. supplies are used according to patient-care needs); equity (e.g. care is accessible to all patients) (16); and 4 statements which measured the final predictor, quality results: "Over the past one year, the hospital has shown steady, measurable improvements in the quality of patient care" $(11,12,25-$ 27). The responses were measured using a 5-point Likert scale ranging from strongly agree (5) to strongly disagree (1). The higher the score, the higher the quality of patient care was perceived. The overall scores of the predictors of the quality of patient care reflect the quality-of-care enhancement index. In addition, data were collected on participants' demographic and professional characteristics including their age, sex, nationality, marital status, unit, occupation, qualifications and total years of experience since graduation and in the current work unit.

The questionnaires were tested for content validity by 5 experts in the same field of the study. The necessary modifications were carried out. The reliability of the internal consistency was done using Cronbach alpha for the Quality of Work Competence and Quality of Patient Care questionnaires. The results proved to be reliable ( $\alpha=0.78$ and 0.70 respectively). A pilot study was carried out on 7 nurses and 7 physicians who were working in the hospital units other than the studied ICUs.

\section{Ethical considerations}

Permission was obtained from the original author of the Quality of Work Competence questionnaire to use it and to make the needed modifications. The ethics committee of the studied hospital approved the study plan. Before embarking on data collection informed consent was obtained from each study participant. All participants were assured that their participation was voluntary and that their privacy and data confidentiality would be maintained. 


\section{Data analysis}

The collected data were revised, coded and entered into the statistical software program SPSS, version 16. Mean and standard deviation (SD) scores were used to describe the scales data, which were converted into mean percentage scores, while frequency and percentages were used to describe the categorical data. Pearson correlation coefficient analysis was used to test the nature of the relationship between 2 quantitative variables - the summation of the overall determinants and predictors and the underlying dimensions. Independent samples $t$-test was used to compare the mean percentage scores of 2 independent groups that followed a normal distribution. All statistical analyses were done using 2-tailed tests and $\alpha$-error of 0.05. $P$-value $<0.05$ was considered to be significant.

\section{Results}

\section{Background characteristics of the sample}

All 49 physicians who participated in this study were of Saudi Arabian nationality. The 75 studied nurses were non-Saudi (Egyptians 1.3\%, South Africans 6.6\% and south-east Asians such as Filipinos 92.1\%). All participants were English speakers. The majority of nurses were females (92.0\%), while $71.4 \%$ of physicians were males; $60.0 \%$ of nurses were married and $77.5 \%$ of physicians were single. The age group $25-<35$ year comprised $54.7 \%$ of nurses and $40.8 \%$ of physicians.

The highest proportion of nurses (82.7\%) had a baccalaureate degree and $17.3 \%$ had a diploma degree in nursing. Of the physicians, the highest percentage (40.8\%) were assistant professors while the lowest $(6.1 \%)$ were associate professors. The highest percentage of nurses (30.7\%) and physicians (36.7\%) were working in the surgical ICU and the lowest in the paediatric ICU (22.7\% and $20.4 \%$ respectively). The modal total years of experience of nurses was $5-<10$ years (53.3\%), which exceeded that of physicians ( $<5$ years, $38.8 \%$ ). Less than 5 years' experience in the current work unit was the common pattern among nurses and physicians.

\section{Nurses' \& physicians' perceptions of determinants of hospital health}

Table 1 shows that the mean percentage score for the focus score enhancement index - the measure of participants' overall perceptions of the determinants of hospital organizational health—was 65.3 (SD 4.2). The highest mean percentage scores were for the domains of teamwork and change motivation [70.5 (SD 1 1.8) and 70.2 (SD 10.4) respectively]. In contrast, the lowest scores were found for mental energy/emotional exhaustion [53.5 (SD 11.6)] and work intensity/tempo [56.2 (SD 12.9)]. The overall mean percentage score of nurses' perceptions on the focus score enhancement index was 66.5 (SD 3.6), significantly higher than that of physicians [63.4 (SD 4.4)] $(t=4.4, P<0.001)$.

There were significant differences between the nurses' and physicians' perceptions of all the individual determinants of hospital health, except for change motivation and teamwork. The highest mean percentage score of nurses was for the domain of competence development [72.7 (SD 10.1)],

\begin{tabular}{|c|c|c|c|c|c|}
\hline Determinants (no. of items) & $\begin{array}{c}\text { Total } \\
\text { Mean score (SD) } \\
(\%)\end{array}$ & $\begin{array}{c}\text { Nurses } \\
\text { Mean score (SD) } \\
(\%)\end{array}$ & $\begin{array}{c}\text { Physicians } \\
\text { Mean score (SD) } \\
(\%)\end{array}$ & $t$-value ${ }^{\mathrm{a}}$ & $P$-value \\
\hline Goal/organizational clarity (6) & $67.6(10.0)$ & $69.1(10.4)$ & $65.2(8.9)$ & 2.2 & 0.033 \\
\hline Performance feedback (7) & $69.5(8.9)$ & $72.3(7.2)$ & $65.2(9.7)$ & 4.7 & $<0.001$ \\
\hline Participatory management (7) & $69.7(9.6)$ & $72.0(9.8)$ & $66.2(3.5)$ & 8.2 & $<0.001$ \\
\hline Leadership (7) & $66.2(10.9)$ & $70.3(9.9)$ & $59.9(9.4)$ & 5.8 & $<0.001$ \\
\hline Organizational efficacy (7) & $68.7(10.7)$ & 70.9 (10.9) & $65.3(9.6)$ & 2.9 & 0.004 \\
\hline Change motivation (7) & $70.2(10.4)$ & $71.0(10.6)$ & $69.1(10.0)$ & 1.0 & 0.320 \\
\hline Competence development (4) & $69.3(11.8)$ & $72.7(10.1)$ & $64.0(12.3)$ & 4.3 & $<0.001$ \\
\hline Teamwork (4) & $70.5(11.8)$ & $71.7(11.2)$ & $68.8(12.6)$ & 1.3 & 0.181 \\
\hline Work climate (6) & $68.4(10.1)$ & $70.4(10.5)$ & $65.2(8.8)$ & 2.9 & 0.005 \\
\hline Mental energy/emotional exhaustion (9) & $53.5(11.6)$ & $50.3(10.4)$ & $58.3(11.8)$ & 3.9 & $<0.001$ \\
\hline Work intensity/tempo (7) & $56.2(12.9)$ & $53.7(12.1)$ & $60.1(13.4)$ & 2.7 & 0.007 \\
\hline Internal communication (9) & $69.6(10.6)$ & $72.0(9.7)$ & $65.9(10.9)$ & 3.3 & 0.002 \\
\hline Overall focus score enhancement index & $65.3(4.2)$ & $66.5(3.6)$ & $63.4(4.4)$ & 4.4 & $<0.001$ \\
\hline
\end{tabular}

andependent samples t-test.

$S D=$ standard deviation . 


\begin{tabular}{|c|c|c|c|c|c|}
\hline Predictors (no. of items) & $\begin{array}{c}\text { Total } \\
\text { Mean score (SD) } \\
(\%)\end{array}$ & $\begin{array}{c}\text { Nurses } \\
\text { Mean score (SD) } \\
(\%)\end{array}$ & $\begin{array}{c}\text { Physicians } \\
\text { Mean score (SD) } \\
(\%)\end{array}$ & $t$-value ${ }^{\mathrm{a}}$ & $P$-value \\
\hline Patient-centred care (4) & $58.7(10.3)$ & $58.7(9.8)$ & $58.8(11.2)$ & 0.09 & 0.930 \\
\hline Effectiveness (3) & $56.1(15.9)$ & $58.1(13.7)$ & $52.9(18.5)$ & 1.7 & 0.094 \\
\hline Safety (3) & $59.1(15.3)$ & $56.6(15.3)$ & $62.9(14.6)$ & 2.3 & 0.024 \\
\hline Timeliness (3) & $62.6(13.6)$ & $63.5(13.6)$ & $61.4(13.7)$ & 0.84 & 0.402 \\
\hline Efficiency (10) & $63.8(12.1)$ & $65.2(10.7)$ & $61.8(13.8)$ & 1.5 & 0.136 \\
\hline Equity (6) & $64.6(10.5)$ & $64.6(10.4)$ & $64.5(10.6)$ & 0.03 & 0.975 \\
\hline Quality results (4) & $69.7(14.3)$ & $70.1(14.3)$ & $69.0(14.3)$ & 0.44 & 0.661 \\
\hline $\begin{array}{l}\text { Overall quality-of-care } \\
\text { enhancement index }\end{array}$ & $58.8(5.3)$ & $59.1(4.6)$ & $58.3(6.2)$ & 0.47 & 0.460 \\
\hline
\end{tabular}

andependent samples t-test.

$S D=$ standard deviation .

and this was significantly higher than physicians' scores [64.0 (SD 12.3)] $(t$ $=4.3, P<0.001)$. On the other hand, the highest mean percentage score of physicians was for change motivation [69.1 (SD 10.0)], although this was not significantly different from nurses' mean percentage scores for this domain $[71.0$ (SD 10.6)] $(t=1.0, P=0.320)$. The lowest scores of nurses were for mental energy/emotional exhaustion and work intensity/tempo [50.3 (SD 10.4) and 53.7 (SD 12.1) respectively] and these were significantly lower than the corresponding scores of physicians [58.3 (SD 11.8) $(t=3.9, P<0.001)$ and $60.1(\mathrm{SD}$ 13.4) $(t=2.7, P=0.007)$ respectively].

\section{Nurses' \& physicians' perceptions of predictors of the quality of patient care}

Table 2 shows that the mean percentage score for the quality-of-care enhancement index-reflecting participants' overall perceptions of the predictors of the quality of patient care - was 58.8 (SD 5.3) The mean percentage score of nurses was 59.1 (SD 4.6) and of physicians was $58.3(\mathrm{SD} 6.2)(t=0.47, P=$ 0.460 ).

The highest mean percentage score for the individual items was for quality results [69.7 (SD 14.3)], and this was the highest scoring predictor among both nurses [70.1 (SD 14.3)] and physicians $[69.0($ SD 14.3) $)(t=0.44, P$ $=0.661)$. The lowest mean percentage score [56.1 (SD 15.9)] was for effectiveness. There were no significant differences between the scores of nurses and physicians on the individual predictors of the quality of patient care, except the safety domain. Nurses' perceptions of safety was the lowest rated domain [56.6 (SD 15.3)], and this was signifcantly lower than among physicians $[62.9(\mathrm{SD} \mathrm{14.6})](t=2.3, P=0.024)$. The lowest mean percentage score of physicians was related to effectiveness [52.9 (SD 18.5)] and this was 58.1 (SD 13.7) for nurses.

\section{Correlations between determinants of hospital health \& predictors of quality of care}

Table 3 shows that there was a significant positive correlation between the mean percentage scores of the participants' overall perceptions of the predictors of the quality of patient care in terms of quality-of-care enhancement index and focus score enhancement index $(r=0.26, P=0.028)$. There were significant positive correlations between the scores on the overall quality-of-care enhancement index and each of the following individual determinants of hospital organizational health: goal/ organizational clarity, leadership, competence development and work climate. Furthermore, significant positive correlations were found between the participants' mean percentage scores on the overall focus score enhancement index and the following individual predictors of quality: patient-centred care, effectiveness, safety, efficiency and equity.

In contrast, the predictor of $\mathrm{pa}$ tient-centred care had no significant positive correlations with any of the 12 individual hospital determinants. Furthermore, 2 of the healthy hospital determinants - performance feedback and teamwork - had no significant correlations with any of the 7 quality of care predictors, while 3 other determinants - efficacy, emotional exhaustion, and excessive work intensity-correlated with only 1 quality of care domain.

\section{Discussion}

The findings of the present study indicated that the participants acknowledged that their hospital was a healthy organization, as reflected in their mean percentage score on the focus score enhancement index [65.3 (SD 4.2)], the measure of overall hospital workplace health. This hospital's good workplace health status could be explained in the light of the supportive social 
environment that the hospital maintains among co-workers and supervisors, peer and team cohesion, utilization of skills, rewards and an emphasis on planning and efficiency. These conditions are the characteristics of any accredited health-care organization wishing to attain high quality patient care. As the studied hospital is a university institution accredited by the Canadian International Accreditation Organization, the affiliated ICUs have specific written guidelines to regulate the performance of patient care and workforce-related aspects. These speculations about the reasons for this hospital's healthy workplace are consistent with the view of Griffin et al. that the availability of mechanisms, programmes, policies, initiatives, actions and practices all create healthy workplaces that provide the health workforce with good physical, mental, psychosocial and organizational conditions. These, in return, contribute to improvements in employees' health and well-being, quality of care and patient safety, organizational performance and societal ou comes (28).
The present study found that teamwork was the highest scoring domain among the hospital health determinants characterizing participants' work environment. Effective health-care organizations are those which are able to encourage the professionals to work and learn together, engage in clinical audit of outcomes together and generate innovation to ensure progress in practice and service. However, sometimes these practices are not designed in a way that facilitates the work and enhances employees' well-being in order to achieve the best outcomes for patients and customers due to inadequate performance feedback. In this respect, Mitchell et al. explained that multiple clinicians working with each other provide the best possible care; each clinician relies upon information and action from other members of the team (29). In contrast, Skela Savič and Pagon found that physicians and nurses had a low level of personal involvement in their organizations and in work teams, while nurses were more likely than were physicians to think that they were subordinated to physicians (30).

Change motivation was the second highest scoring hospital health determinant, and this could be considered as a key factor in team effectiveness. The degree of participants' motivation to change is a critical precursor to successful implementation of organizational change and the strength of the hospital workplace health. Good teams that create a friendly atmosphere among team members may stimulate health professionals to accept change in their work environment, particularly if it is introduced to facilitate work and maintain a safer workplace. Caldwell et al. argued that much of the responsibility for implementing changes within healthcare organizations is given to groups or teams (31). Also, Lemieux-Charles and McGuire pointed out the importance of teams in implementing change in health-care organizations and suggested that effective team dynamics are related to team success (32). However, Burningham and West found that comparatively little research has investigated

\begin{tabular}{|c|c|c|c|c|c|c|c|c|}
\hline \multirow{2}{*}{$\begin{array}{l}\text { Determinants of hospital } \\
\text { health }\end{array}$} & \multicolumn{7}{|c|}{ Predictors of quality of patient care } & \multirow{2}{*}{$\begin{array}{c}\text { Quality- } \\
\text { of-care } \\
\text { enhancement } \\
\text { index }\end{array}$} \\
\hline & $\begin{array}{l}\text { Patient- } \\
\text { centred } \\
\text { care }\end{array}$ & Effectiveness & Safety & Timeliness & Efficiency & Equity & $\begin{array}{l}\text { Quality } \\
\text { results }\end{array}$ & \\
\hline Goal/organizational clarity & 0.19 & $0.27^{*}$ & -0.01 & $0.40^{* *}$ & 0.12 & 0.19 & $0.34^{*}$ & $0.31^{* *}$ \\
\hline Performance feedback & -0.20 & -0.01 & -0.11 & 0.21 & 0.05 & 0.01 & 0.04 & -0.01 \\
\hline Participatory management & 0.10 & 0.16 & -0.18 & $0.25^{*}$ & $0.25^{*}$ & 0.10 & $0.25^{*}$ & 0.18 \\
\hline Leadership & 0.05 & $0.27^{*}$ & -0.01 & $0.44^{* *}$ & 0.13 & 0.21 & 0.22 & $0.26^{*}$ \\
\hline Efficacy & -0.06 & 0.18 & -0.11 & $0.31^{*}$ & 0.10 & 0.19 & 0.19 & 0.16 \\
\hline Change motivation & 0.09 & $0.32^{* *}$ & -0.04 & $0.35^{* *}$ & 0.07 & 0.20 & 0.18 & 0.23 \\
\hline Competence development & 0.18 & $0.24^{*}$ & -0.06 & $0.42^{* *}$ & 0.16 & $0.34^{* *}$ & $0.31^{* *}$ & $0.32^{* *}$ \\
\hline Teamwork & 0.10 & 0.17 & -0.15 & 0.20 & -0.02 & 0.20 & 0.18 & 0.13 \\
\hline Work climate & 0.08 & $0.26^{*}$ & 0.06 & $0.26^{*}$ & 0.12 & 0.21 & 0.20 & $0.24^{*}$ \\
\hline $\begin{array}{l}\text { Mental energy/emotional } \\
\text { exhaustion }\end{array}$ & 0.02 & 0.22 & $0.37^{* *}$ & -0.09 & -0.14 & 0.02 & -0.23 & 0.05 \\
\hline Work intensity/tempo & 0.07 & 0.02 & 0.13 & -0.13 & -0.07 & $1.00^{* *}$ & -0.12 & -0.02 \\
\hline Internal communication & 0.06 & 0.12 & -0.18 & $0.27^{*}$ & 0.19 & $0.30^{*}$ & 0.21 & 0.19 \\
\hline $\begin{array}{l}\text { Focus score enhancement } \\
\text { index }\end{array}$ & $0.43^{* *}$ & $0.54^{* *}$ & $0.28^{*}$ & 0.14 & $0.45^{* *}$ & $0.51^{* *}$ & 0.21 & $0.26^{*}$ \\
\hline
\end{tabular}

Significant correlations (2-tailed): ${ }^{*} P<0.05 ;{ }^{*} P<0.01$. 
how teams within organizations can either facilitate or inhibit organizational attempts to implement new ideas (33).

In contrast to these positive findings, the present study also provided empirical data about perceptions of high levels of emotional exhaustion and undue work intensity among our participants. These variables were significantly more perceived by the nurses than the physicians. Emotional exhaustion and inability to cope with work intensity are inevitable problems for staff who work in ICUs, who deal with physical and emotional problems of seriously ill patients while also having to cope with teamwork and deal with complex management structures and conflicting demands at all hours of the day and night. Cronqvist et al. argued that health professionals suffer from tension specifically related to occupational stress and that stress at work is greater in ICUs (34). Professionals who work in these units might experience excessive workload, lower work satisfaction and psychological disorders (35). Hence, the risks of stress and health problems are manifested when work demands do not match employees' needs, expectations or skills (36).

Other factors that could intensify nurses' feelings of excessive mental energy/emotional exhaustion and work intensity/tempo are the culture, the payment system and variations in educational background. As all of the studied nurses were expatriates with different cultures, religions, value systems and languages, this cultural diversity could lead to culture shock and communication problems among nurses with other health care customers. The presence of a culturally diverse workforce in health-care environments is an emerging global reality. Not only are nurses delivering care to culturally diverse clients, the nurses themselves may come from different cultural and educational backgrounds (37). To date, health care for the citizens of Saudi Arabia has been provided largely by a foreign labour force, the vast majority of whom are non-Arabic speaking (38). A lack of respect for acquired skills, loss of status and reverse culture shock are recurring problems in many healthcare organizations, especially among expatriates (39). Bonache found that expatriates, as compared with domestic employees, experienced greater job overload and greater pressure from the visibility of their jobs. In addition, their functions were not always completely defined, so they may experience a higher degree of uncertainty and role ambiguity (40). Moreover, unfair payment compared with others, in particular Saudi citizens, and the possibility of termination of employment in case of failure to meet career requirements and professional accomplishments could cause them to feel higher levels of emotional exhaustion and undue work intensity. Research on expatriates' attitudes has uncovered low levels of salary satisfaction among these workers. For example, Black et al. asserted that $77.0 \%$ of expatriate employees were highly unsatisfied with their compensation systems (41).

All these problems perceived by the participants, in addition to relatively ineffective leadership, especially according to physicians (reflected in their significantly lower scores on the item on leadership), could contribute to their perceptions of a relative poorer quality of patient care, as reflected in the overall quality-of-care enhancement score [58.8 (SD 5.3)]. There was a significant positive correlation between the mean percentage scores of the participants on quality-of-patient care enhancement and focus score enhancement $(r=0.26)$. However, most of the healthy hospital determinants - such as performance feedback, teamwork, efficacy, emotional exhaustion and work intensity - had few or no significant correlations with the predictors of the quality of patient care. Therefore, these determinants could not be conveniently designed to enhance the quality of patient care to the anticipated standard.
Our participants gave lower ratings to the domains of effectiveness, patientcentred care and safe care. These findings could be explained in the light of the insufficient support given by the leadership to a patient-centred approach and providing safe care based on scientific knowledge in daily practice, as well as non-compliance with the related policies and standards of patient care by all health-care professionals. In this respect, Hughes mentioned that, despite being a relatively new field of enquiry, particularly in terms of how patient safety and quality are now defined, the need to improve the quality and safety of care is the responsibility of all clinicians, all healthcare providers and all health-care leaders and managers (42). A range of organizational and management best practices provide a foundation for enhancing patient safety and quality of care. Experts highlight the importance of establishing a culture of safety founded on a model of proactive leadership and commitment to beliefs and values that continuously seek to minimize patient harm through adoption of well-established policies and procedures (43). Additional management strategies that enhance patient and staff safety and quality improvement include integration of quality measures on an ongoing basis, while collaborative initiatives between health-care managers and clinical leaders are an important catalyst to organizational change.

A study on family-centred care has shown that patient-centred care has positive effects on patients (44). However, critical-care providers may be less amenable to adopting the principles of patient-centred care due to the high workload in ICUs. Although the nurse's role is to provide care in a safe way, in our study nurses rated safety in their work situation significantly lower than did physicians. This finding could be explained in the light of Hughes' argument that a large part of the demands of patient care is centred on the work of nurses (45). Nurses spend more time than physicians do caring for patients 
and this could help them to evaluate safety more accurately.

\section{Conclusions}

We conclude that, although there were several organizational determinants of the hospital that correlated with the quality of patient care, among the 12 determinants of organizational health, competence development correlated positively with the greatest number of predictors of patient care quality. Most of the other hospital heath determinants (e.g. performance feedback, teamwork, organizational efficacy, mental energy/ emotional exhaustion and work intensity/tempo) had few or no significant correlations with the predictors of patient care quality. The findings from this study can serve as part of the planning process for health-care facilities when there is a need to evaluate the effectiveness of hospitals, departments and units. We also conclude that controlling the emotional exhaustion and work intensity of health-care professionals and working on the enhancement of care effectiveness and patient-centred care are required to improve the wellbeing of the workforce and the quality of patient care. Furthermore, more emphasis is required to enhance teamwork and to develop the competencies of health-care professionals in order to increase the hospital's capacity to function effectively within the context of patients' needs. Policy-makers and regulators should include patient safety, patient-centeredness and effectiveness as dimensions of quality in its own right in strategic and other policy documentation.

Competing interests: None declared.

\section{References}

1. Omoyemiju MA, Adediwura AA. A study of teachers' perception of schools' organizational health in Osun State. World J Educ Res. 2011;1:165-70.

2. A framework for public reporting on healthy work environments in Ontario healthcare settings. Ontario: Ontario Health Quality Council; 2010:7 (http://www.grahamlowe.ca/ documents/243/healthy_work_environment_framework_-march2010.pdf, accessed 24 July 2014).

3. Hearld LR, Alexander JA, Fraser I, Jiang HJ. Review: how do hospital organizational structure and processes affect quality of care? A critical review of research methods. Med Care Res Rev. 2008 Jun;65(3):259-99. PMID:18089769

4. Healthy workplaces: a model for action for employers, workers, policy-makers and practitioners. Geneva: World Health Organization; 2010 (http://www.who.int/occupational_ health/publications/healthy_workplaces_model.pdf, accessed 24 July 2014).

5. Hoy WK, Feldman JA. Organizational health: the concept and its measure. In: Hoy WK, DiPaola MF, editors. Essential ideas for the reform of American schools (PB). Charlotte (NC): Information Age Publishing; 2007:49-66.

6. Alman D. Organizational health. Improving organizational performance and employee well-being, 2010 [Internet] (http:// www.slideshare.net/davidalman/organisational-health, accessed 24 July 2014).

7. Stanford N. Organizational health: an integrated approach to building optimum performance. London: Kogan Page; 2013: 22-3.

8. Fisher P. Organizational health: a unique 12-factor, 4-tier research based model. Victoria (BC): Fisher \& Associates Solutions Inc.; 2007 http://www.fisherandassociates.org/pdf/ OrgHealthDescription_10.pdf, accessed 24 July 2014).

9. Fisher P. Organizational effectiveness and capacity: the critical role of organizational health. Victoria (BC): Fisher \& Associates Solutions Inc.; 2009 (http://www.fisherandassociates.org/pdf/ OrgEffectivenessCapacity_\%20Jun_09.pdf, accessed 1 July 2014).

10. MacNeil AJ, Prater DL, Busch S. The effects of school culture and climate on student achievement. Int J Leadership Educ. 2009;12(1):73-84.

11. Arnetz BB. Physicians' view of their work environment and organisation. Psychother Psychosom. 1997;66(3):155-62. PMID:9176910
12. Arnetz BB. Subjective indicators as a gauge for improving organizational well-being. An attempt to apply the cognitive activation theory to organizations. Psychoneuroendocrinology. 2005 Nov;30(10):1022-6. PMID:15955637

13. Hansson A. Determinants of individual and organizational health in human service professions. In: Digital comprehensive summaries of Uppsala dissertations from the Faculty of Medicine 348. Uppsala: University of Uppsala; 2008.

14. Baker DP, Day R, Salas E. Teamwork as an essential component of high-reliability organizations. Health Serv Res. 2006 Aug;41(4 Pt 2) 4, Part II:1576-98. PMID:16898980

15. Lohr KN, Donaldson MS, Harris-Wehling J. Medicare: a strategy for quality assurance, $\mathrm{V}$ : Quality of care in a changing health care environment. QRB Qual Rev Bull. 1992 Apr;18(4):120-6. PMID:1630793

16. Reason JT. Human error. Cambridge, UK: Cambridge University Press; 1990.

17. Piquette D, Reeves S, LeBlanc VR. Stressful intensive care unit medical crises: How individual responses impact on team performance. Crit Care Med. 2009 Apr;37(4):1251-5. PMID:19242320

18. Bruhn A, Lind M, Svensson L. Arbetsmiljo och arbetsmiljoarbete I Svenska kyrkan-en fallstudie [Work environment and work environment initiatives in the Church of Sweden-a case study.] Orebro, Sweden: University of Orebro, Department of Social Sciences; 2005.

19. Lundstrom T, Pugliese G, Bartley J, Cox J, Guither C. Organizational and environmental factors that affect worker health and safety and patient outcomes. Am J Infect Control. 2002 Apr;30(2):93-106. PMID:11944001

20. Van Bogaert P, Meulemans H, Clarke S, Vermeyen K, Van de Heyning P. Hospital nurse practice environment, burnout, job outcomes and quality of care: test of a structural equation model. J Adv Nurs. 2009 Oct;65(10):2175-85. PMID:20568322

21. Arnetz BB. Techno-stress: a prospective psychophysiological study of the impact of a controlled stress-reduction program in advanced telecommunication systems design work. J Occup Environ Med. 1996 Jan;38(1):53-65. PMID:8871332

22. Arnetz BB. Staff perception of the impact of health care transformation on quality of care. Int J Qual Health Care. 1999 Aug;11(4):345-51. PMID:10501605 
23. Battles J. TeamSTEPPS ${ }^{\text {TM }}$ teamwork perceptions questionnaire (T-TPQ) manual. Washington (DC): American Institutes for Research; 2010 (http://teamstepps.ahrq.gov/Teamwork_Perception_Questionnaire.pdf, accessed 24 July 2014).

24. Institute of Medicine. Crossing the quality chasm: a new health system for the 21st century. Washington (DC): National Academy Press; 2001.

25. Shortell SM, O'Brien JL, Carman JM, Foster RW, Hughes EF, Boerstler $\mathrm{H}$, et al. Assessing the impact of continuous quality improvement/total quality management: concept versus implementation. Health Serv Res. 1995 Jun;30(2):377-401. PMID:7782222

26. Pomey MP, Contandriopoulos AP, François P, Bertrand D. Accreditation: a tool for organizational change in hospitals? Int Health Care Qual Assur Inc Leadersh Health Serv. 2004;17(23):113-24. PMID:15301268

27. El-Jardali F, Jamal D, Dimassi H, Ammar W, Tchaghchaghian $\mathrm{V}$. The impact of hospital accreditation on quality of care perception of Lebanese nurses. Int J Qual Health Care. 2008 Oct;20(5):363-71. PMID:18596050

28. Griffin P. El-Jardali F, Tucker D, Grinspun D, Bajnok I, Shamian J. What's the fuss about? Why do we need healthy work environments for nurses anyway? HR Resources Database, November [Internet]. Ontario: Longwoods; 2006 (http://www.longwoods.com/content/18026, accessed 24 July 2014).

29. Mitchell P. Wynia M, Golden R, McNellis B, Okun S, Webb CE, Rohrbach V, Kohorn IV. Core principles and values of effective team-based health care. Washington (DC): Institute of Medicine; 2012:1-30 (http://www.iom.edu/ /media/Files/ Perspectives-Files/2012/Discussion-Papers/VSRT-TeamBased-Care-Principles-Values.pdf, accessed 4 July 2014).

30. Skela Savic B, Pagon M. Relationship between nurses and physicians in terms of organizational culture: who is responsible for subordination of nurses? Croat Med J. 2008 Jun;49(3):33443. PMID:18581611

31. Caldwell DF, Chatman J, O'Reilly CA 3rd, Ormiston M, Lapiz M. Implementing strategic change in a health care system: the importance of leadership and change readiness. Health Care Manage Rev. 2008 Apr-Jun;33(2):124-33. PMID:18360163

32. Lemieux-Charles L, McGuire WL. What do we know about health care team effectiveness? A review of the literature. Med Care Res Rev. 2006 Jun;63(3):263-300. PMID:16651394

33. Burningham C, West MA. Individual, climate, and group interaction processes as predictors of work team innovation. Smal Group Res. 1995;26:106-17.

34. Cronqvist A, Lützén K, Nyström M. Nurses' lived experiences of moral stress support in the intensive care context. J Nurs Manag. 2006 Jul;14(5):405-13. PMID:16787476
35. Oates RK, Oates P. Stress and mental health in neonatal intensive care units. Arch Dis Child. 1995 October;72(2):F107-10.

36. de Cássia Fogaça $M$, de Carvalho WB, de Albuquerque Cítero V, Nogueira-Martins LA. Preliminary study about occupational stress of physicians and nurses in pediatric and neonatal intensive care units: the balance between effort and reward. Rev Lat Am Enfermagem. 2010 Jan-Feb;18(1):67-72. PMID: 20428699

37. Tortumluoglu G. The implications of transcultural nursing models in the provision of culturally competent care. ICUs and Nursing Web Journal. 2006 issue 25:1-11 (http://www. nooruse.ee/e-ope/mitmek_oendus/transcultural_nursing. pdf, accessed 24 July 2014)

38. Luna L. Culturally competent health care: a challenge for nurses in Saudi Arabia. J Transcult Nurs. 1998 Jan-Jun;9(2):8-14. PMID:9856009

39. Stahl GK, Miller E, Tung R. Toward the boundaryless career. A closer look at the expatriate career concept and the perceived implications of an international assignment. J World Bus. 2002;37:216-27.

40. Bonache J. Job satisfaction among expatriates, repatriates and domestic employees: the perceived impact of international assignments on work-related variables. Person Rev. 2005;34:110-24.

41. Black JS, Gregersen HB, Mendenhal ME. Toward a theoretical framework of repatriation adjustment. J Int Bus Stud. 1992;23(4):737-60.

42. Hughes RG. Preface. In: Hughes RG, editor. Patient safety and quality: An evidence-based handbook for nurses. Rockville (MD): Agency for Healthcare Research and Quality, US Department of Health and Human Services; 2008:v-ix.

43. Prevention of the adverse health effects of the health care system-evidence review. Vancouver (BC): Population and Public Health, Ministry of Healthy Living and Sport; 2010 (http://www.health.gov.bc.ca/public-health/core-programs/ disease-prevention/adverse-health/evidence-reviews.html, accessed 24 July 2014).

44. Davidson JE. Family-centered care: meeting the needs of patients' families and helping families adapt to critical illness. Crit Care Nurse. 2009 Jun;29(3):28-34. PMID:19487778

45. Hughes RG. Nurses at the "Sharp End" of patient care. In: Hughes RG, editor. Patient safety and quality. An evidencebased handbook for nurses. Rockville (MD): Agency for Healthcare Research and Quality; 2008:1-7. 